\title{
Non pharmacological treatments in fibromyalgia
}

\section{Il trattamento non farmacologico della sindrome fibromialgica}

\begin{abstract}
R. Casale ${ }^{1}$, M. Cazzola ${ }^{2}$, G. Arioli ${ }^{3}$, R.H. Gracely ${ }^{4}$, F. Ceccherelli ${ }^{5}$, F. Atzeni ${ }^{6}$, S. Stisi $^{7}$, G. Cassisi ${ }^{8}$, L. Altomonte ${ }^{9}$, A. Alciati ${ }^{10}$, G. Leardini ${ }^{11}$, R. Gorla ${ }^{12}$, A. Marsico ${ }^{13}$, R. Torta ${ }^{14}$, M.A. Giamberardino ${ }^{15}$, D. Buskila ${ }^{16}$, M. Spath ${ }^{17}$, F. Marinangeli ${ }^{18}$, L. Bazzichi ${ }^{19}$, M. Di Franco ${ }^{20}$, G. Biasi ${ }^{21}$, F. Salaffi ${ }^{22}$, R. Carignola ${ }^{23}$, P. Sarzi-Puttini' ${ }^{6}$ (Italian Fibromyalgia Network)

${ }^{1}$ Department of Clinical Neurophysiology and Pain Rehabilitation Unit, Foundation Salvatore Maugeri, IRCCS, Scientific Institute of Montescano, Montescano (PV), Italy; ${ }^{2}$ Unit of Rehabilitative Medicine "Hospital of Circolo", Saronno (VA), Italy; ${ }^{3}$ Division of Rehabilitative Medicine and Rheumatology, General Hospital of Pieve di Coriano (Mantua), Italy; ${ }^{4}$ Department of Medicine, University of Michigan Health System, Ann Arbor, USA; ${ }^{5}$ IOV (Veneto Cancer Institute), IRCCS, Department of Pharmacology and Anesthesiology, University of Padua, Italy; ${ }^{6}$ Rheumatology Unit, L.Sacco University Hospital, Milan, Italy; ${ }^{7}$ Rheumatology Unit, “G.Rummo" Hospital, Benevento, Italy; ${ }^{8}$ Rheumatology Branch, Specialist Out-patients Department, Belluno, Italy;

${ }^{9}$ UOC of Rheumatology Hospital S. Eugenio, Rome, Italy; ${ }^{10}$ Department of Psychiatry, L. Sacco University Hospital, Milan, Italy; ${ }^{11}$ Rheumatology Unit, SS Giovanni e Paolo Hospital, Venice, Italy; ${ }^{2}$ Rheumatology and Clinical Immunology, Spedali Civili and University of Brescia, Italy; ${ }^{13}$ Rheumatology Unit, Hospital of Taranto, Taranto, Italy; ${ }^{14}$ Department of Neuroscience, University of Turin, A.S.O. San Giovanni Battista of Turin, Turin, Italy; ${ }^{15}$ Ce.S.I. "G. D'Annunzio" Foundation, Department of Medicine and Science of Aging, “G. D'Annunzio”, University of Chieti, Italy; ${ }^{16}$ Department of Medicine H, Soroka Medical Center and Faculty of Health Sciences, Ben Gurion University, Beer Sheva, Israel; ${ }^{17}$ Friedrich-Baur-Institute, University of Munich, Germany; ${ }^{18}$ Department of Anesthesiology and Pain Medicine, L'Aquila University, L'Aquila, Italy; ${ }^{19}$ Department of Internal Medicine, Division of Rheumatology, S. Chiara Hospital, University of Pisa, Italy; ${ }^{20}$ Chair of Rheumatology, University la Sapienza Rome, Rome, Italy; ${ }^{21}$ Unit of Rheumatology, University of Siena, Siena, Italy; ${ }^{22}$ Department of Rheumatology, Polytechnic University of the Marche Region, Ancona, Italy; ${ }^{23}$ S.C.D.U. Internal Medicine I, Department of Clinical and Biological Science, University of Turin, Italy
\end{abstract}

Competing interests: none declared

\section{RIASSUNTO}

La fibromialgia è una sindrome complessa associata ad una significativa riduzione della qualità di vita e della funzione con sostanziali costi economici. Una volta che la diagnosi venga fatta, il personale sanitario dovrebbe cercare di migliorare le funzioni del paziente e di minimizzare il dolore. I pazienti affetti da fibromialgia frequentemente utilizzano terapia complementari, indicando con questo la loro insoddisfazione e la sostanziale inefficacia della terapia medica tradizionale, in particolare quella farmacologica. Attualmente, le terapie farmacologiche presentano uno scoraggiante rapporto costo/beneficio sia in relazione allo scarso controllo dei sintomi sia per l'alta incidenza di effetti collaterali. I programmi di terapia interdisciplinare hanno evidenziato di migliorare la sintomatologia in maniera più significativa rispetto alle monoterapie. Le terapie fisiche, la riabilitazione e le terapie alternative sono generalmente percepite per essere più "naturali", per avere meno effetti collaterali, e in qualche modo, per essere più efficaci. In questa review, l'esercizio fisico e la terapia cognitivo-comportamentale multimodale sono presentate come le forme più accettate e più efficaci nell'area della terapia non farmacologica.

Reumatismo, 2008; 60: Supplemento 1: 59-69

\section{INTRODUCTION}

$\mathrm{T}_{\mathrm{m}}^{\mathrm{o}}$ o fully answer the complex question of what modes of non pharmacological treatments are useful for fibromyalgia (FM) one should ask dif-

Corresponding author:

Piercarlo Sarzi-Puttini, MD

Director of Rheumatology Unit

L. Sacco University Hospital, Milan, Italy

E-mail: sarzi@tiscali.it ferent layers of questions, and as with peeling layers of onions, be prepared to shed some tears.

The first painful question, or layer of the onion, is related to understanding patients' complaints. Patients who experience recurrent as well as persistent physical symptoms without any objective evidence are too often classified as "psychosomatic disorders" or worse as "non disease" (see Sarzi this issue). This is often the case with FM. This leads to the use of alternative medicines such as physi- 
cal exercise and other therapies that are used in fancy and pseudophilosophical ways, and it renders evaluation of possible positive results nearly impossible in the absence of a defined diagnosis and recognised treatment protocols.

The second onion layer is related to the possible presence of FM subset as well as to the erratic presentation of multiple painful muscle spots and correlated symptoms (1).

A third layer recognizes the presence of different approach to management objectives and treatment choices by the various medical professionals involved in the treatment of FM. For instance occupational therapists consider an increasing level of activity as the major treatment objective, followed by pain control and fatigue management while physical therapists are more concerned with improving exercise tolerance and fitness followed by pain control and functional abilities. Fatigue management and endurance exercise are the most frequent interventional targets across both professions (2).

The last and most important layer addresses the presence of a neuropathic component in the manifestation of pain in FM. In other words, if the pain expression in FM is only due to nociceptive pain (peripheral and related to an activation in muscle nociceptors), or if the pain felt by FM patients in their muscle is more or less dependent on functional alteration in the sensory decoding of afferent inputs as well as in altered descending pain control systems. These last theories have gained strength recently based on several studies as well as clinical reports (see other chapters in this issue). This is the most important point to keep in mind when prescribing non pharmacological treatments in FM, as the two types of pain, namely neuropathic and nociceptive, require different non pharmacological approaches (3). Unfortunately, this concept is rarely considered when tailoring non pharmacological treatments for pain control, in general, and particularly, in FM. This oversight can result in inappropriate application of otherwise useful non pharmacological pain control techniques.. For the sake of systematic organization, the most commonly used forms of non pharmacological treatment in FM can be divided into four major categories:

- Physical therapies

- Movement and exercises.

- Cognitive-behavioural treatments.

- Complementary and alternative treatments.

Of note, the majority of non pharmacological treatment studies utilise multimodal therapies, which renders comparison and critical analysis on the efficacy of a single treatment difficult and a possible guideline on these techniques a source of major criticism.

\section{PHYSICAL THERAPIES}

The definition of physical therapies encompasses all treatment using a physical activity or technique to induce some therapeutic effect. These techniques are mainly used in a rehabilitation context, although some are also used as complementary and alternative treatments. These two approaches are quite divergent, however. In the rehabilitation context, physical therapies are used on the basis of their ascertained mechanism of action (i.e., the activation of the spinal gate, release of endogenous opiates, local metabolic action, etc.), but when used as alternative treatments this linkage is completely lost.

Physical therapies include thermal (both heat and cold), mechanical, light, electrical and magnetic stimulation. In this context, acupuncture as well as mechanical stimulation that is induced by some form of massage (i.e. connective tissue massage) can be considered as particular forms of physical treatment. Each technique claims its own mechanism of action, although peer-reviewed evidence of their effectiveness in FM is lacking and recent reviews have reached non homogeneous conclusions. While some reviews, based only on few randomized, controlled trials, are cautious in stating efficacy, they strongly suggest conducting more sound studies and demonstrating a long-term, effective intervention for managing the symptoms associated with FM (4). Other reviews, which have included anecdotal evidence or small, observational physiotherapy studies, indicate that physical therapies can be efficacious for different symptoms (5).

\section{Heat and cold}

Although beneficial in other forms of muscle pain, local application of cold therapy by means of ice cubes or cooling sprays does not seem to have any efficacy in FM. Cold sprays are used within the stretch and spray techniques (see below). On the contrary whole body criotherapy at $-67^{\circ} \mathrm{C}$ seems to have some short-term effect on the number of active trigger points and intensity of pain. No data are available on its long-term efficacy (6). Superficial heat and deep heat with infrared and ultrasound application as well as the local thermal effect induced 
by stroking massages have been always reported as beneficial by FM patients $(7,8)$. When deep heat has been compared with sertraline, an antidepressant, it fails to show any better results (9). Heat is also a fundamental factor in balneotherapy (see below). The real efficacy of both superficial as well as deep heat is still matter for research, however.

\section{Electrical stimulation \& TENS}

Electrical currents are, by far, the most used physical therapy in pain medicine. In fibromyalgia they have been applied transcutaneously to stimulate peripheral nerves (TENS) $(10,11)$ as well as to transcranially to stimulate cortical areas of the brain (12). Stimulation of motor cortex areas is better achieved through magnetic stimulation. Preliminary but encouraging results have been obtained by this newly introduced methodology $(13,14)$. Traditional electrical currents have been used at high and low intensity (12) as well as at high and low frequency $(10,11)$ and by applying interferential patterns (7). Hydrogalvanic baths have historical merit, although they are evidently still in use with some success in treating pain (15). One review article quotes TENS as a useful methodology to control specific symptoms such as localised musculoskeletal pain (5) while a more recent review is more cautious on the general efficacy of electrical current (4). What can be said is that TENS and related techniques can be beneficial in treating specific, contingent and localized pain problems while they do not have any sort of effect on FM as a whole. This concept is extensible to most of the non pharmacological treatments considered in this review.

\section{Laser Light}

Few and conflicting data are available on the use of LASER in FM although a possible mechanismbased efficacy has been demonstrated (16). Some studies have reported no effects $(17,18)$ while others have found a statistically significant reduction in both spontaneous and mechanically evoked pain $(19,20)$. Comparison of various treatment protocols is difficult, however, due to varying lengths of emission wave and emission power across different, non-standardised protocols. Moreover almost all studies that employed laser treatment used low power laser that cannot reach deep muscle layers where taught band and trigger points are usually located.

As far as we know only one study has used light bathing (exposure to a source of with light) as a therapy; however, results in FM patients did not differ from those in the placebo group (21).

\section{Massage}

The efficacy of massage varies depending on the type and intensity of mechanical stimulation exerted. Connective tissue massage is a technique that applies mechanical stimulation of varying intensity in a predetermined pattern rather than following the trigger point sites identified by the patient. This technique uses two different stimulation intensities, and the mechanism of action relies on gate control as well as on the release of endogenous opiates. Connective tissue massage has been shown to improve pain and reduce the number of trigger points (22-24) while other forms of massage, i.e., relaxation massages, only result in a general sensation of pleasantness and wellness (25); although this is very much appreciated by patients $(26,27)$, it does not reflect a clinical improvement. Relaxation massage, therefore, is more appropriately designated as an alternative treatment than a physical therapy.

\section{Acupuncture}

In single clinical trials acupuncture shows interesting results $(28,29)$ that are confirmed by systematic reviews (30). Acupuncture has been shown not only to decrease the number and intensity of painful spots but also to modify neuro-hormonal parameters in these patients (29). It is worth noting that some FM patients do not like the acupuncture sensation; and in some cases, exacerbation of symptoms has been reported, which confirms the clinical observations of the extreme instability of the sensory-reaction system in these patients $(30,31)$. Dry needling is a form of acupuncture performed with normal needles that are usually used for injected therapies (28 gauge). Dry needling of trigger points seems to have some long lasting effect on trigger-point pain in nearly $30 \%$ of patients (32); this may be due to activation of the endogenous opioid system as its analgesic effect is reversed by naloxone. A systematic review and meta-analysis of randomised controlled trials on dry needling and acupuncture in the management of myofascial trigger point pain has been published recently and focuses on the substantial need for more extensive, controlled studies (33).

\section{Balneotherapy}

Thermal therapy is one of the oldest treatment modalities for osteoarthropathies. Historically, the 
definition of "balneotherapy" has been used only to define treatments with thermal or mineral waters, while the definition of hydrotherapy was reserved for water therapy without particular thermal or mineral contents. More recently, the definition of balneotherapy has been applied to all therapeutic procedures performed in water. This placed balneotherapy midway between physical therapy and cognitive behavioural therapy in as much as the environment (thermal resorts), the water temperature $\left(37^{\circ} \mathrm{C}\right)$ and the execution of exercise can contribute to the positive results of this treatment in FM. The exact amount of efficacy of each single component has been challenged by a recent study in which balneotherapy alone and balneotherapy plus water exercise did not differ in results (34). To render evaluation more difficult, exercise in water versus a dry environment does not result in substantial differences (35). Positive results can be perceived after 6 weeks to 6 months according to different authors (36-38). Sauna and mud bath treatments have been used with some positive results in uncontrolled studies; these results may be related to some sort of stress induced analgesia $(39,40)$.

\section{MOVEMENT AND EXERCISES}

The majority of FM patients complain of severe functional limitations in activities of daily living (41), and not surprisingly, most FM patients are physically deconditioned (42). Active as well as passive mobilization have been used although recent reviews do not provide clear results on their efficacy. Active physical exercise, both aerobic and anaerobic, has been identified as one of the pivotal treatments in FM, although patients quite often have difficulties in starting and maintaining exercise programs (43).

The internet provides access to so many types of physical training and exercises that is almost impossible to take all them into account. Moreover, sometimes terms such as "movement" or "physical exercise" are proposed without giving any specifics concerning the type of exercise that should be done, the duration, or the intensity of the training. In this respect the term physical exercise is similar to the term "drug".

In both cases describing a treatment as aerobic or anaerobic or drug is not enough, specific details of the treatment must be provided. A very recent meta-analysis reviewed all studies that were identified on the Cochrane Central Register for Con- trolled Trials up to July 2005 suggesting moderate evidence that aerobic-only exercise training at American College of Sports Medicine (ACSM)recommended intensity levels has positive effects on global well-being and physical function, primarily, and, also a possible effect on pain and tender points. Strength and flexibility remain underevaluated; however, strength training may have a positive effect on FM symptoms. This meta-analysis suggests that aerobic-only training has beneficial effects on physical function and some FM symptoms.

Strength-only training may improve FM symptoms, but requires further study (44). Table I provides an overview of data from the Cochrane Review on exercise for FM (45). However, data on the long-term efficacy of movement and exercise in controlling the clinical picture are still lacking. Aerobic exercises can be performed in a traditional "dry" environment as well as in water via deep water running programs, hydrokinesis therapy in heated water, and in the Spa environment $(35,46$, 47). In general, both aerobic and anaerobic exercises have been associated with educational and occupational programs (48-52). While the shortterm efficacy of exercise is generally accepted, the critical issue appears to be long-term compliance. Most studies report a lack of persistent effects associated with a failure to maintain the exercise program (53).

Passive movements induced by manipulative techniques have been also used. They encompass several methodologies such as vertebral manipulations, finger pressure on trigger points, craniosacral manipulation techniques and other forms of chiropractics.

A controlled study on the efficacy of chiropractics has shown a reduction in pain and disability levels assessed using the Oswestry Pain Disability Index and Neck Disability Index. Although positive, these results should be considered with caution and a generalization of the efficacy of these practices is untenable (54). Stretch and spray technique is a popular form of myofascial pain therapy in rehabilitation.

The technique combines the effect of rapid cooling of the overlying skin using a vapocoolant such as fluorimethane with passive elongation of muscles. Despite its popularity only one study reports a reduction of pain at the trigger points measured by pressure algometer and VAS in myofascial pain patients; as far as we know no data are available on FM patients. 
Table I - Major findings of Cochrane revision on "Exercise for treating fibromyalgia syndrome" from: Busch AJ, Barber KAR, Overend TJ, Peloso PMJ, Schachter CL. Exercise for treating fibromyalgia syndrome. Cochrane Database of Systematic Reviews 2002, Issue 3.

\begin{tabular}{|c|c|c|}
\hline $\begin{array}{l}\text { Aerobic } \\
\text { exercise }\end{array}$ & $\begin{array}{l}4 \text { studies } \\
\text { cycling, walking, } \\
\text { whole body } \\
\text { or dance aerobics } \\
\text { over } 6 \text { to } 20 \text { weeks } \\
\text { ( } 2 \text { studies tested } \\
\text { at } 2 \text { or } 4.5 \text { years } \\
\text { also). }\end{array}$ & $\begin{array}{l}\text { Aerobic fitness/performance improved on average by } 17 \% \text { in patients who did aerobic } \\
\text { exercises and } 0.5 \% \text { in patients who did not } \\
\text { - thresholds to pain improved on average by } 28 \% \text { in patients who did aerobic exercises } \\
\text { but worsened by } 7 \% \text { in patients who did not } \\
\text { - pain intensity decreased on average by } 11 \% \text { in patients who did aerobic exercises } \\
\text { but increased by } 1.6 \% \text { in patients who did not } \\
\text { - overall well-being improved in patients who did aerobic exercises } \\
\text { - sleep, fatigue, sense of well-being, confidence in performing tasks and physical function } \\
\text { improved in some studies but did not in other studies } \\
\text { - psychological function, such as depression or anxiety, improved equally in patients } \\
\text { who exercised and in patients who did not }\end{array}$ \\
\hline Strength & One study & - pain, muscle fitness and mood improved in patients who did strength exercises more than \\
\hline exercises & $\begin{array}{l}\text { squats, knee } \\
\text { and trunk extensions } \\
\text { and bench press } \\
\text { over } 21 \text { weeks }\end{array}$ & $\begin{array}{l}\text { in patients who did not } \\
\text { - sleep and fatigue changed about equally in patients who exercised and in patients } \\
\text { who did not }\end{array}$ \\
\hline $\begin{array}{l}\text { Combined } \\
\text { exercises }\end{array}$ & $\begin{array}{l}\text { One study } \\
\text { Aerobic program } \\
\text { (walking) strength } \\
\text { and flexibility } \\
\text { exercises } \\
\text { over } 6 \text { weeks }\end{array}$ & $\begin{array}{l}\text { - aerobic fitness and thresholds to pain improved more in patients who had a combined } \\
\text { exercise program compared to patients who did not }\end{array}$ \\
\hline Combination & Two studies & - there were no differences between the patients who exercised with biofeedback or without \\
\hline $\begin{array}{l}\text { of exercise } \\
\text { and another } \\
\text { treatment }\end{array}$ & $\begin{array}{l}\overline{\text { Aerobic exercise }} \\
\text { plus education } \\
\text { and aerobic exercise } \\
\text { plus biofeedback }\end{array}$ & biofeedback \\
\hline $\begin{array}{l}\text { Longer } \\
\text { follow-up }\end{array}$ & $\begin{array}{l}\text { Three studies that } \\
\text { tested exercises for } \\
\text { longer than } 21 \text { weeks }\end{array}$ & $\begin{array}{l}\text { - One study showed that patients reported better physical function and greater confidence } \\
\text { in performing daily tasks after } 1 \text { year of exercise. } \\
\text { - The other study showed that patients who exercised for } 6 \text { months had greater confidence } \\
\text { in performing daily tasks, had less fatigue and showed more improvement in the 6-minute }\end{array}$ \\
\hline
\end{tabular}

\section{COGNITIVE BEHAVIORAL THERAPY}

Along with physical exercise training, cognitive behavioral therapy is a recognized treatment for FM. Cognitive behavioral therapy (CBT) is a composite of two approaches, cognitive therapy and behavioral therapy. Today CBT refers to a large number of component methods. The term CBT is nonspecific and similar to the term "drug". Similar to the generic term "physical exercise" discussed above, describing a treatment as CBT or drug is not enough, specific details of the treatment must be provided.

The behavior therapy component of CBT includes a number of techniques that are centered on the core tenants of operant and classical conditioning in psychology. In applications to treatment, the classification is expanded to a number of methods that include relaxation, sleep hygiene, pacing of activity, scheduling social and leisure activities, pain coping, education, and assertiveness training (55). The combination of this large group of procedures along with cognitive therapy provides the components of the CBT "toolbox". This concept of a toolbox is important when considering CBT for FM patients since meaningful discussion and evaluation must take into account the specific tools that are used.

Co-morbidities including stiffness, fatigue; and problems with sleep, concentration and memory 
are more or less associated in almost all FM patients. It is not surprising that many patients experience interpersonal distress and behavioral deficits. Since CBT has been shown to be particularly effective in distress and behavior disorders, it is logical to apply CBT methods to FM. This approach assumes that a patient can be helped significantly by addressing the many non-pain aspects of FM.

A growing literature describes CBT treatment of FM and has been addressed by meta analyses and reviews (55-59).

A similar literature describes CBT approaches to related disorders such as irritable bowel syndrome, and the concepts learned in these disorders are useful for the treatment of FM. The available evidence can be divided into studies of CBT alone, CBT in combination with other pharmacological and nonpharmacological therapies, the nature of CBT effects, patient subgrouping and tailoring CBT components to specific treatment.

Data emerging from these reviews and meta-analyses suggest that such single method CBT (smCBT) treatments may be the least efficacious in terms of multiple outcome measures (60).

Several studies of education programs and relaxation have not demonstrated effects that persist in follow up evaluations. Improved results have been obtained with multiple method CBT (mmCBT), which can include a number of components such as cognitive restructuring, pain-coping, problem solving, goal setting, increasing activity levels, pacing, stress management, and adjustment of pain medications in addition to education and relaxation $(60,61)$.

The effectiveness of this approach was demonstrated in a study in which two groups received "standard" care of pharmacological therapy and exercise instruction, and one of these groups received a minimal package of six, one-hour group sessions of CBT that focused on improving function. At one year, twice the number of patients receiving standard care plus CBT reported significant improvement in comparison to the group receiving standard care only. At two years most patients continued to report benefits.

The principle that mmCBT is superior to smCBT can be extended to multi-dimensional therapy in which mmCBT is paired with other traditional therapies.

The two most common are pharmacological treatment and exercise therapy (see this chapter). Most reviews have discussed the positive effects of drugs associated with various form of CBT. One issue is that the efficacy is coupled with the short-term effects of these drugs such that improvements may be lost if the drug is discontinued.

Many reviews of CBT for fibromyalgia conclude that the effects are modest. It is important to note that this is true for all treatments of FMS, including the new generation of pharmacological agents. The fact that only one-third of participants respond to an active therapy is a challenge for the development of future treatments.

It also raises interesting questions such as whether there is a small responder group that responds to any form of treatment, or a broader group, subsets of which respond to different treatments. MmCBT targets significant components of FM and related disorders, enjoys superior compliance in comparison to exercise, and results in positive effects that persist after treatment.

\section{COMPLEMENTARY AND ALTERNATIVE TREATMENTS}

As many as $87 \%$ of the general population of tertiary care patients have tried at least one complementary and alternative treatment (62) (Table II). Terms such as non-conventional, complementary and alternative treatments encompass all therapeu-

Table II - Use of complementary and alternative medical treatments at a tertiary care center (62).

\begin{tabular}{|lc|}
\hline $\begin{array}{l}\text { Techniques and unconventional } \\
\text { treatments }\end{array}$ & $\begin{array}{c}\text { No patients (289) } \\
\%\end{array}$ \\
\hline Physical exercises & 48 \\
Prayer & 45 \\
Massage & 44 \\
Chiropractics & 37 \\
Weight control & 20 \\
Relaxation techniques & 17 \\
Aromatherapy & 15 \\
Music therapy & 12 \\
Acupuncture & 11 \\
Counseling \& therapeutic groups & 11 \\
Homeopathy & 10 \\
Acupressure & 10 \\
Magneto therapy & 9 \\
Plantar reflexology & 9 \\
Pranotherapy & 8 \\
Biofeedback & 8 \\
Therapeutic painting & 5 \\
Others & 8 \\
Patients using at least one of the listed therapies & 87 \\
\hline
\end{tabular}


tic and healing techniques that are not recognized by the scientific community due to lack of pathophysiological evidence and mechanisms of action that are able to support their supposed efficacy. All of the treatments cited below are popular with patients and available (with payment) on several sites on the web; our search terms simply matched the treatment type with "fibromyalgia".

Five of these are considered complementary or alternative treatments that are more or less openly used in FM:

a) complete theoretical systems such as homeopathy, naturopathy and anthroposophy, traditional Chinese medicine, and ayurvedic medicine;

b) body-mind techniques;

c) nutriceutics;

d) physical manipulation;

e) energetic medicine encompassing pranotherapy, reiki, and healing touch.

On a recent American survey (62) the most popular alternative treatments included physical exercise (48\%), prayer (45\%), massage (44\%), and chiropractics $(37 \%)$. Along with these treatments $83 \%$ of these patients use at least one vitamin and 52\% use some sort of food supplementation.

\section{Complete therapeutic systems}

Among complete therapeutic systems, homeopathy is used the most. Its efficacy in FM, as for almost of its clinical application, has never been demonstrated in clinically controlled trials (63).

Ayurvedic, anthroposophy and traditional Chinese medicine as well as homeopathy are based on principles that are alien to Western biology and too far from the writer's competence to be reasonably and fully reported here.

\section{Body-mind techniques}

This definition encompasses those techniques that are used to improve mental control over bodily functions.

Some of them have been accepted already and used in the context of traditional Western medicine such as behavioural and cognitive therapies, support groups, and music therapy in its broader meaning, while others are still outside official medicine such as meditation, therapeutic prayer, and mentallydriven healing techniques.

Although not considered in this review, it is worth noting the interesting results obtained by these body-mind techniques: they seem to be able to diminish the number and the pain intensity of tender points, and they can improve depression, anxiety and physical performance for over two years (64). Apparently, similar results have been obtained with meditation techniques (65).

Some clinical benefits have been obtained in a therapy-resistant group of FM patients by means of hypnosis (66).

\section{Nutriceutics and dietary supplementation}

As many as 52\% of FM patients use some form of alimentary supplementation including vitamins $\mathrm{C}$ (35\%), E (31\%), and B complex (25\%) and Magnesium $(29 \%)$.

Green tea $(24 \%)$ is popular as an antioxidant; weight control programs (20\%) are also popular. Some alimentary supplements have demonstrated some utility in reducing pain intensity and fatigue such as methionin (67-69) and magnesium $(70,71)$, while others did not show any improvement (72). Moreover, there are various other nutraceutics that claim some success in controlling FM-related symptoms such as sleep disturbance and early sensation of fatigue.

Unfortunately, as for almost all of the treatments reported in this section, controlled studies are lacking.

Some benefits have been claimed using melatonin (73), hypericum perforatum (St. John's wort) and dietary control (74).

\section{Physical manipulation}

Chiropratics and other forms of manipulation based on mobilization or even manipulation of body segments like manual medical techniques (Meigne) and all forms of non medical massage. It seems that the chiropractic approach is useful in the treatment of FM.

One study compared FM patients who experienced 4 weeks of treatment to patients on a wait list and registered a temporary decrease in cervical and lumbar pain in the treated group. These patients were also taking medication (75).

\section{CONCLUSIONS}

FM patients frequently use alternative therapies, strongly indicating their dissatisfaction with traditional medical therapies as well as the substantial ineffectiveness of these traditional therapies, especially pharmacological treatment.

At present, pharmacological treatments for FMS have a rather discouraging ratio poor symptom con- 
trol associated with a high incidence of side effects. Physical therapy, rehabilitation and alternative therapies are generally perceived to be more "natural," to have fewer adverse effects, and in some way, to be more effective. In this context physical exercise and multimodal cognitive behavioural therapy seem to be the more accepted and beneficial forms of non pharmacological therapy. Anedoctal evidence and small observational studies using physical therapies, show some good results.

These results are encouraging premises for larger, more systematic and methodologically sound, randomised, controlled clinical trials which will evaluate the real effectiveness of physical therapy modalities for managing FM.

It is clear that, similar to successful treatment of other disorders, the most efficacious treatment of FM will combine the major elements of pharmacotherapy, exercise, physical therapy and mmCBT. Evidence that efficacy is inversely related to disease duration suggests that this treatment program should be initiated as quickly as possible after diagnosis.

As noted above, multi-modal treatment may succeed for a number of reasons. The results of recent studies that have identified distinct subgroups in FM and studies that predict treatment response indicate that it will be useful, if not essential, to tailor the choice of treatment components to individual patients.

Current knowledge is beginning to suggest prediction criteria for treatment success, and future studies that include detailed genotyping and phenotyping promise to vastly increase the ability to match treatment packages to patients. Such knowledge will also identify healthy individuals who are at risk for developing FM and signal prophylactic treatment in a manner that is similar to current interventions for diabetes or heart disease. Current evidence suggests that CBT, exercise and to a lesser extent, physical therapies will remain important components in these individualized treatments by playing a pivotal role in the long-term management of FM.

The need for multimodal therapy in FM comes from different sources. It relies on several factors: first, the potential that all patients possess the same mechanistic disorder, but specific patients only respond to specific treatments and the probability of receiving this specific treatment is greater when a multidisciplinary approach has been planned; second, pain and dysfunction may be mediated by different mechanisms, and these different mechanisms are targeted by the different therapeutic components; third, specific patients may need to be exposed to multiple methods to achieve improvement, and such multiple methods are naturally provided by multimodal therapies; fourth, the outcome measures may only assess a subset of the relevant domain of the disorder, and multiple methods are more likely to target these evaluated domains.

While there seems to be no single best treatment option, a multidisciplinary approach combining these therapies in a well-balanced program may be the most promising strategy.

Non-pharmacological treatments can be recommended in the treatment of FM, although in the interest of time or financial restrictions it is essential to focus medical prescriptions only on those therapies that are supported by scientific evidence.

\section{SUMMARY}

Fibromyalgia is a complex syndrome associated with significant impairment in quality of life and function and with substantial financial costs. Once the diagnosis is made, providers should aim to increase patients' function and minimize pain. Fibromyalgia patients frequently use alternative therapies, strongly indicating both their dissatisfaction with and the substantial ineffectiveness of traditional medical therapy, especially pharmacological treatments. At present, pharmacological treatments for fibromyalgia have a rather discouraging cost/benefit ratio in terms of poor symptom control and high incidence of side effects. The interdisciplinary treatment programs have been shown to improve subjective pain with greater success than monotherapy.

Physical therapies, rehabilitation and alternative therapies are generally perceived to be more "natural," to have fewer adverse effects, and in some way, to be more effective. In this review, physical exercise and multimodal cognitive behavioural therapy are presented as the more accepted and beneficial forms of nonpharmacological therapy.

Key words - Multimodal cognitive behavioural, rehabilitation, alternative therapies.

Parole chiave - Terapia cognitivo-comportamentale, riabilitazione, terapia alternativa. 


\section{REFERENCES}

1. Giesecke T, Williams DA, Harris RE, Cupps TR, Tian X, Tian TX, Gracely RH, Clauw DJ. Subgrouping of fibromyalgia patients on the basis of pressure-pain thresholds and psychological factors. Arthritis Rheum 2003; 48: 2916-22.

2. Sim J, Adams N. Therapeutic approaches to fibromyalgia syndrome in the United Kingdom: a survey of occupational therapists and physical therapists. Eur J Pain 2003; 7: 173-80.

3. Woolf CJ, Bennett GJ, Doherty M, Dubner R, Kidd B, Koltzenburg M, Lipton R, Loeser JD, Payne R, Torebjork E. Towards a mechanism-based classification of pain? Pain 1998; 77: 227-9.

4. Gur A. Physical therapy modalities in management of fibromyalgia. Curr Pharm Des 2006; 12: 329-59.

5. Offenbächer M, Stucki G. Physical therapy in the treatment of fibromyalgia. Scand J Rheumatol 2000; 113: $78-85$.

6. Gutenbrunner C, Englert G, Neuen-Lahusen M, Gehrke A. Controlled study on effects of cold chamber exposures $\left(-67^{\circ} \mathrm{C}, 3 \mathrm{~min}\right)$ in fibromyalgia. Akt Rheumatol 1999; 24: 77-84.

7. Citak-Karakaya I, Akbayrak T, Demirturk F et al. Short and long-term results of connective tissue manipulation and combined ultrasound therapy in patients with fibromyalgia. J Manipulative Physiol Ther 2006; 29: 524-8.

8. Almeida TF, Roizenblatt S, Benedito-Silva AA, Tufik $\mathrm{S}$. The effect of combined therapy (ultrasound and interferential current) on pain and sleep in fibromyalgia. Pain 2003; 104: 665-72.

9. Gonzalez-Viejo MA, Avellanet M, Hernandez-Morcuente MI. A comparative study of fibromyalgia treatment: ultrasonography and physiotherapy versus sertraline treatment. Ann Readapt Med Phys 2005; 48: 610-15.

10. Sunshine W, Field TF, Quintino O, Fierro K et al. Fibromyalgia benefits from massage therapy and transcutaneous electrical stimulation. J Clin Rheumatol 1996; 2: 18-22.

11. Kaada B. Treatment of fibromyalgia by low-frequency trancutaneous nerve stimulation. Tidsskr Nor Laegeforen 1989; 109: 2992-5.

12. Fregni F, Gimenes R, Valle AC et al. A randomized, sham-controlled, proof of principle study of transcranial direct current stimulation for the treatment of pain in fibromyalgia. Arthritis Rheum 2006; 54: 3988-98.

13. Sampson SM, Rome JD, Rummans TA. Slow-frequency rTMS reduces fibromyalgia pain. Pain Med 2006; 2: 115-18.

14. Passard A, Attal N, Benadhira R, Brasseur L, Saba G, Sichere $\mathrm{P}$ et al. Effects of unilateral ripetitive transcranial magnetic stimulation of the motor cortex on chronic widespread pain in fibromyalgia. Brain 2007; 130: 2661-70.

15. Gunter V, Mur E, Kinigadner U, Miller C. Fibromyalgia: the effect of relaxation and hydrogalvanic bath therapy on the subjective pain experience. Clin Rheumatol 1994; 13: 573-8.

16. Walker J. Relief from chronic pain by low power laser irradiation. J Neurol Transm 1977; 40: 305-8.

17. Matsutani LA, Marques AP, Ferreira EA, Assumpção A, Lage LV, Casarotto RA, Pereira CA. Effects of muscle stretching exercises with and without laser therapy at tender points for patients with fibromyalgia. Clin Exp Rheumatol 2007; 25: 410-5.

18. Waylonis GW, Wilke S, O'Toole D, Waylonis DA, Waylonis DB. Chronic myofascial pain: management by low-output helium-neon laser therapy. Arch Phys Med Rehabil 1988; 69: 1017-20.

19. Gur A, Karakoc M, Nas K, Cevik R et al. Effects of low power laser and low dose amitriptyline therapy on clinical symptoms and quality of life in fibromyalgia : a single-blind, palcebo-controlled trial. Rheumatol Int 2002; 22: 188-93.

20. Yurtkuran M, Celiktas M. A randomized controlled trial of balneotherapy in the treatment of patients with primary fibromyalgia syndrome. Phys Rehab Kur Med 1996; 6: 109-12.

21. Pearl DJ, Lue F, MacLean AW et al. The effects of bright light treatment on the symptoms of fibromyalgia. J Rheumatol 1996; 23: 896-902.

22. Casale R, Sommovigo B, Bellotti P. Connective tissue massage (bindegewebsmassage) as a non-pharmacological treatment for fibromyalgia. Rheumatic Pain Treatment, IASP special interest group on rheumatic pain Freeburg, August 18-19, 2001.

23. Brattberg G. Connective tissue massage in the treatment of fibromyalgia. Eur J Pain 1999; 3: 235-45.

24. Citak-Karakaya I, Akbayrak T, Demirturk F et al. Short and long-term results of connective tissue manipulation and combined ultrasound therapy in patients with fibromyalgia. J Manipulative Physiol Ther 2006; 29: 524-8.

25. Haanen HCM, Hoenderdos HTW, van Romunde LKJ et al. Controlled trial of hypnotherapyin the treatment of refractory fibromyalgia. J Rheumatol 1991; 18 : $72-5$.

26. Harris RE, Claw DJ. The use of complementary medical therapies in the management of myofascial pain disorder. Curr Pain Headache Rep 2002; 6, 370-4.

27. Pioro-Boisset M, Esdaile JM, Fitzchareles MA, Altenative Medicine use in fibromyalgia. Arthritis Care Res 1996; 9: 13-7.

28. Cassisi G, Roncaglione A, Ceccherelli F, Donolato C, Gagliardi G, Todesco S. Trattamento agopunturale della fibromialgia primaria. Confronto con mianserina. G.Ital. Riflessot. Agopunt 1994; 6: 5-9.

29. Sprott H, Franke S, Kluge H, Hein G. Pain treatment of fibromyalgia with acupuncture. Rheumatol Int 1998; 18: 35-6.

30. Berman BM, Ezzo J, Hadhazy V, Swyers JP. Is acupuncture effective in the treatment of fibromyalgia? J Fam Pract 1999; 48: 213-8.

31. Offenbacher M, Stuki G. Physical therapy in the treatment of fibromyalgia. Scand J Rheumatol 2000; 29 (113 Suppl): 78-85. 
32. Lewit K. The needle effect in the relief of myofascial pain. Pain 1979; 6: 83-90.

33. Tough EA, White AR, Cummings TM, Richards SH, Campbell JL. Acupuncture and dry needling in the management of myofascial trigger point pain: a systematic review and meta-analysis of randomised controlled trials. Eur J Pain 2008 in print.

34. Altan L, Bingol U, Aykac M et al. Investigation of the effects of pool-based exercise on fibromyalgia syndrome. Rheumatol Int 2004; 24: 272-7.

35. Assis MR, Silva LE, Alves AM, et al. A randomized controlled trial of deep water running: clinical effectivenes of aquatic exercise to treat fibromyalgia. Arthritis Rheum 2006; 55: 57-65.

36. Donmez A, Karagulle MZ, Tercan N et al. SPA therapy in fibromyalgia: a randomised controlled clinic study. Rheumatol Int 2005; 26: 168-72.

37. Buskila D, Abu-Shakra M, Neumann L et al. Balneotherapy for fibromyalgia at the dead sea. Rheumatol Int 2001; 20: 105-108.

38. Gusi N, Tomas-Carus P, Hakkinen A et al. Exercise in waist-high warm water decreases pain and improves health-related quality of life and strength in the lower extremities in women with fibromyalgia. Arthritis Rheum 2006; 55: 66-73.

39. Piso U, Gutenbrunner C, Gehrke A. Effekte einer sechsswochingen Saunatherapie auf die Schmerzschwelle an den ACR-Tenderpoints bei der generalisierten Tendomyopathie. Phys Rehab Kur Med 1998; 8: 156.

40. Fioravanti A, Perpignano G, Tirri G et al. Effects of mud-bath treatment on fibromyalgia patients: a randomized clinical trial. Rheumatol Int 2007; 27 : 1157 61.

41. Mannerkorpi K, Burckhardt CS, Bjelle A. Physical performance characteristics of women with fibromyalgia. Arthritis Care Res 1994; 7: 123-9.

42. Bennett RM, Clark SR, Goldberg L, Nelson D, Bonafede RP, Porter J, Specht D. Aerobic fitness in patients with fibrositis. A controlled study of respiratory gas exchange and 133xenon clearance from exercising muscle. Arthritis Rheum. 1989; 32: 454-60.

43. Rossy LA, Buckelew SP, Dorr N et al. A meta-analysis of fibromyalgia treatment interventions. Ann Behav Med 1999; 21: 180-91.

44. Busch AJ, Schachter CL, Overend TJ, Peloso PM, Barber KA. Exercise for fibromyalgia: a systematic review J Rheumatol 2008; 35: 1130-44.

45. Busch AJ, Barber KAR, Overend TJ, Peloso PMJ, Schachter CL. Exercise for treating fibromyalgia syndrome. Cochrane Database of Systematic Reviews 2002, Issue 3.

46. Munguìa-Izquierdo D, Legaz-Arrese A. Exercise in warm water decreases pain and improves cognitive function in middle-aged women with fibromyalgia. Clin Exp Rheumatol 2007; 25: 823-30.

47. Zijlstra1, van de Laar MAFJ, Bernelot Moens HJ et al. Spa treatment for primary fibromyalgia syndrome: a combination of thalassotherapy, exercise and patient education improves symptoms and quality of life. Rheumatology 2005; 44: 539-46.
48. Burckhardt CS, Mannerkorpi K, Hedenberg L et al. A randomized controlled clinical trial of education and physical training for women with fibromyalgia. J Rheumatol 1994; 21: 714-20.

49. Gowans SE, deHueck A, Voss S et al. A randomized, controlled trial of exercise and education for individuals with fibromyalgia. Arthritis Care Res 1999; 12: 120-8.

50. Martin L, Nutting A, MacIntosh BR, et al. An exercise program in the treatment of fibromyalgia. J Rheumatol 1996; 23: 1050-3.

51. McCain GA, Bell DA, Mai FM et al. A controlled study of the effects of a supervised cardiovascular fitness training program on the manifestations of primary fibromyalgia. Arthritis Rheum 1988; 31: 1135-41.

52. Wigers GH, Stiles TC, Vogel PA. Effects of aerobic exercise versus stress management treatment in fibromyalgia: a 4.5 year prospective study. Scand J Rheumatol 1996; 25: 77-86.

53. Rossy LA, Buckelew SP, Dorr N et al. A meta-analysis of fibromyalgia treatment interventions. Ann Behav Med 1999; 21: 180-91.

54. Blunt KL, Rajwani MH, Guerriero RC. The effectiveness of chiropratic management of fibromyalgia patients: a pilot study. J Manipulative Physiol Ther 1997; 20: 389-99.

55. Williams DA. Psychological and behavioural therapies in fibromyalgia and related syndromes. Best Pract Res Clin Rheumatol 2003; 17: 649-65.

56. Goldenberg DL, Burckhardt C, Crofford L. Management of fibromyalgia syndrome. JAMA 2004; 292: 2388-95.

57. Hadhazy VA, Ezzo J, Creamer P, Berman BM. Mindbody therapies for the treatment of fibromyalgia. A systematic review. J Rheumatol 2000; 27: 2911-8.

58. Sim J, Adams N. Systematic review of randomized controlled trials of nonpharmacological interventions for fibromyalgia. Clin J Pain 2002; 18: 324-36.

59. Rossy LA, Buckelew SP, Dorr N, Hagglund KJ, Thayer JF, McIntosh MJ, Hewett JE, Johnson JC. A metaanalysis of fibromyalgia treatment interventions. Ann Behav Med 1999; 21: 180-91.

60. van Koulil S, Effting M, Kraaimaat FW, van Lankveld W, van Helmond T, Cats H, van Riel PL, de Jong AJ, Haverman JF, Evers AW. Cognitive-behavioural therapies and exercise programmes for patients with fibromyalgia: state of the art and future directions. Ann Rheum Dis 2007; 66: 571-81.

61. Williams DA, Cary MA, Groner KH, Chaplin W, Glazer LJ, Rodriguez AM, Clauw DJ. Improving physical functional status in patients with fibromyalgia: a brief cognitive behavioral intervention. J Rheumatol 2002; 29: 1280-6.

62. Wainer-Roedler DL, Elkin PL, Vincent A et al. Use of complementary and alternative medical treatment program at a tertiary care center. Mayo Clin Proc 2005; 80: 55-60.

63. Gemmel H, Jacobson BH, Banfield K. Homeopathic Rhus Toxicodendron in treatment of fibromyalgia. Chiropratic J Aust 1991; 21: 2-6. 
64. Bennett RM, Burkhardt CS, Clark SR. Group treatment of fibromyalgia: a 6 month outpatient program. J Rheumatol 1996; 23: 521-8.

65. Kaplan KH, Goldenberg DL, Galvin-Nadeau M. The impact of a meditation-based stress reduction program on fibromyalgia. Gen Hosp Psychiatry 1993; 15: 284-9.

66. Simms R.W., Controlled trials of therapy in fibromyalgia syndrome. Balliere Clin Rheum 1994; 8: 917-34.

67. Jacobsen S, Danneskiold-Samsoe B, Andersen RB. Oral S-Adenosylmethionine in primary fibromyalgia: a double-blind clinical evaluation. Scand. J Rheumatol 1991; 20: 294-302.

68. Tavoni A, Vitali C, Bombardieri S. Evaluation of Sadenosylmethionine in primary fibromyalgia: a double blind cross-over study. Am J Med 1987; 83: 107-10.

69. Volkmann H, Norregard J, Jacobsen S, DanneskioldSamsoe B, Knoke G, Nehrdich D. Double-blind, placebo-controlled cross-over study of intravenous S-adenosyl-methionine in patients with fibromyalgia. Scand J Rheumatol 1997; 26: 206-11.
70. Abraham G, Flechas J. Management of fibromyalgia: rationale for use of magnesium and malic acid. $\mathrm{J} \mathrm{Nu}-$ tritional Med 1992; 3: 49-59.

71. Cox IM, Campbell MI, Dowson D. Red blood cell magnesium and chronic fatigue syndrome. Lancet 1991; 337: 757-60.

72. Russel IJ, Michalek JE, Flechs JD. Treatment of fibromyalgia syndropme with super malic; a randomized, double-blind placebo controlled crossover pilot study. J Rheumatol 1995; 22: 935-58.

73. Citera G, Arias A, Maldonado-Cocco Ja et al. The effect of melatonin in patients with fibromyalgia: a pilot study. Clin Rheumatol 2000; 19: 9 -13.

74. Dykman KD, Tone C, Ford C et al. The effects of nutritional supplements on the symptoms of fibromyalgia and chronic fatigue syndrome. Integr Physiol Behav Sci, 1998; 33: 61-71.

75. Blunt KI, Rajwani MH, Guerriero RC. The effectiveness of chiropractic management of fibromyalgia patients: a pilot study. J Manipulative Physiological Ther 1997; 20: 389-9. 